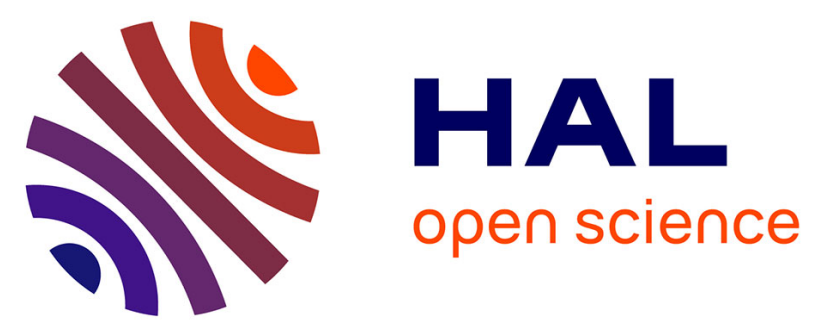

\title{
18F-FDOPA PET/CT Uptake Parameters Correlate with Catecholamine Secretion in Human Pheochromocytomas
}

Sophie Moog, Sebastien Houy, Elodie Chevalier, Stéphane Ory, Georges Weryha, Marion Rame, Marc Klein, Laurent Brunaud, Stephane Gasman, Thomas Cuny

\section{To cite this version:}

Sophie Moog, Sebastien Houy, Elodie Chevalier, Stéphane Ory, Georges Weryha, et al.. 18F-FDOPA PET/CT Uptake Parameters Correlate with Catecholamine Secretion in Human Pheochromocytomas. Neuroendocrinology, 2018, 107 (3), pp.228-236. 10.1159/000491578 . hal-02323272

\section{HAL Id: hal-02323272 \\ https://hal.science/hal-02323272}

Submitted on 22 Oct 2019

HAL is a multi-disciplinary open access archive for the deposit and dissemination of scientific research documents, whether they are published or not. The documents may come from teaching and research institutions in France or abroad, or from public or private research centers.
L'archive ouverte pluridisciplinaire HAL, est destinée au dépôt et à la diffusion de documents scientifiques de niveau recherche, publiés ou non, émanant des établissements d'enseignement et de recherche français ou étrangers, des laboratoires publics ou privés. 


\title{
${ }^{18}$ F-FDOPA PET/CT Uptake Parameters Correlate with Catecholamine Secretion in Human Pheochromocytomas
}

\author{
Sophie Moog ${ }^{a}$ b Sébastien Houy ${ }^{b}$ Elodie Chevalier ${ }^{c}$ \\ Stéphane Ory ${ }^{\mathrm{b}}$ Georges Weryha ${ }^{\mathrm{a}}$ Marion Rame ${ }^{\mathrm{b}}$ Marc Klein $^{\mathrm{a}}$ \\ Laurent Brunaud $^{d}$ Stéphane Gasman ${ }^{b}$ Thomas Cuny ${ }^{\mathrm{e}}$ \\ ${ }^{a}$ Department of Endocrinology, University Hospital of Nancy, Nancy, France; ${ }^{b}$ Institut des Neurosciences Cellulaires \\ et Intégratives (INCI), Centre National de la Recherche Scientifique (CNRS) et Université de Strasbourg, Strasbourg, \\ France; ${ }^{C}$ Department of Nuclear Medicine, University Hospital of Nancy, Nancy, France; ${ }^{d}$ Department of Endocrine \\ Surgery, University Hospital of Nancy, Nancy, France; ${ }^{e}$ Aix-Marseille Université, INSERM, U1251, Marseille Medical \\ Genetics and AP-HM, Department of Endocrinology, Hôpital de la Conception, Centre de Référence des Maladies \\ Rares Hypophysaires HYPO, Marseille, France
}

\section{Keywords \\ Catecholamine - Chromaffin cells - Endocrine tumor . \\ Exocytosis · Pheochromocytoma $\cdot{ }^{18} \mathrm{~F}-\mathrm{FDOPA}$ PET/CT}

\begin{abstract}
Background: ${ }^{18} \mathrm{~F}-\mathrm{FDOPA}$ positron emission tomography/ computed tomography (PET/CT) is a sensitive nuclear imaging technology for the diagnosis of pheochromocytomas (PHEO). However, its utility in determining predictive factors for the secretion of catecholamines remains poorly studied. Methods: Thirty-nine histologically confirmed PHEO were included in this retrospective single-center study. Patients underwent ${ }^{18} \mathrm{~F}$-FDOPA PET/CT before surgery, with an evaluation of several uptake parameters (standardized uptake values $\left[S U V_{\text {max }}\right.$ and $\left.S U V_{\text {mean }}\right]$ and the metabolic burden [MB] calculated as follows: $\mathrm{MB}=\mathrm{SUV}_{\text {mean }} \times$ tumor volume) and measurement of plasma and/or urinary metanephrine (MN), normetanephrine (NM), and chromogranin A. Thirty-five patients were screened for germline mutations in the RET, $S D H x$, and $V H L$ genes. Once resected, primary cultures of
\end{abstract}

5 PHEO were used for real-time measurement of catecholamine release by carbon fiber amperometry. Results: The MB of the PHEO positively correlated with 24-h urinary excretion of NM $(r=0.64, p<0.0001), \mathrm{MN}(r=0.49, p=0.002)$, combined MN and NM $(r=0.75, p<0.0001)$, and eventually plasma free levels of NM $(r=0.55, p=0.006)$. In the mutated patients ( $3 S D H D, 2 S D H B, 3 N F 1,1 \mathrm{VHL}$, and 3 RET), a similar correlation was observed between $M B$ and 24-h urinary combined MN and NM ( $r=0.86, p=0.0012)$. For the first time, we demonstrate a positive correlation between the PHEO-

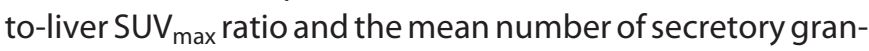
ule fusion events of the corresponding PHEO cells revealed by amperometric spikes $(p=0.01)$. Conclusion: While the ${ }^{18} \mathrm{~F}-\mathrm{FDOPA}$ PET/CT MB of PHEO strongly correlates with the concentration of $\mathrm{MN}$, amperometric recordings suggest that ${ }^{18}$ F-FDOPA uptake could be enhanced by overactivity of catecholamine exocytosis.

(c) 2018 S. Karger AG, Basel

S. Moog and S. Houy contributed equally as co-first authors, and S. Gasman and T. Cuny as co-last authors, to this work.

\section{KARGER}

(c) 2018 S. Karger AG, Basel

E-Mail karger@karger.com

www.karger.com/nen
Thomas Cuny, MD, PhD

Department of Endocrinology, Hôpital de la Conception

Centre de Référence des Maladies Rares Hypophysaires HYPO

FR-13005 Marseille (France)

E-Mail thomas.cuny@ap-hm.fr 


\section{Introduction}

Pheochromocytomas (PHEO) define tumors arising from secreting adrenomedullary chromaffin cells that commonly produce one or more catecholamines whose degradation results in the release of metanephrine (MN) and normetanephrine (NM) in plasma. Hypersecretion of catecholamines can cause sustained or paroxysmal elevations in blood pressure, headaches, episodic profuse sweating, and palpitations and can ultimately be the cause of severe cardiovascular morbidity [1,2]. Currently, nearly $40 \%$ of PHEO encountered in the clinic can be associated with a syndrome of predisposition in which the tumors are likely recurrent, numerous, and/or metastatic [3-5].

Besides hormonal evaluation, radiological and nuclear medical imaging procedures are required for the diagnosis of PHEO, including the search for metastasis. ${ }^{18} \mathrm{~F}$ FDOPA positron emission tomography/computed tomography $\left({ }^{18} \mathrm{~F}\right.$-FDOPA PET/CT) has both high sensitivity and high specificity for the characterization of these tumors, especially in cases of small hereditary PHEO [6, 7]. The principle of ${ }^{18} \mathrm{~F}$-FDOPA PET/CT is based on the property of neuroendocrine tumor cells to take up L-DOPA via the neutral amino acid transporter system L (LAT1 or LAT2), to decarboxylate it into dopamine thanks to amino acid decarboxylase, and to eventually store amino acids (such as DOPA) and their biogenic amines in vesicles [8]. A recent study suggests a positive correlation between the intensity of ${ }^{18} \mathrm{~F}$-FDOPA uptake in patients with PHEO and their respective level of urinary MN [9]. However, the relation between the ${ }^{18} \mathrm{~F}-\mathrm{FDOPA} \mathrm{PET} / \mathrm{CT}$ uptake parameters and the cellular pattern of catecholamine secretion in the corresponding tumors may need further clarification and new insights. A suitable technique for investigating this issue is carbon fiber amperometry, allowing the real-time measurement of catecholamine secretion at the level of a single cell [10].

Further information focusing on the potential correlation between ${ }^{18} \mathrm{~F}$-FDOPA uptake and tumor cell secretion could be of a great interest to optimize both medical and surgical approaches to treatment of these potentially lifethreatening tumors.

The aim of our study was therefore (1) to evaluate the relation between ${ }^{18} \mathrm{~F}$-FDOPA PET/CT uptake and the secretion of catecholamines in patients with histologically confirmed PHEO and (2) to compare, in a subgroup of PHEO cases, the characteristics of ${ }^{18} \mathrm{~F}$-FDOPA PET/CT uptake with the profiles of tumor cell secretion recorded in vitro by carbon fiber amperometry.

\section{Subjects and Methods}

\section{Patient Population}

This retrospective single-center study enrolled 39 patients with histologically confirmed PHEO operated between January 2012 and June 2017 at the Department of Endocrine Surgery. Patients with parasympathetic paragangliomas were excluded from the study, because they usually do not produce catecholamines. None of the patients had a metastatic PHEO at the time of the study.

All patients underwent ${ }^{18} \mathrm{~F}$-FDOPA PET/CT at the time of initial diagnosis and a complete endocrinological evaluation before surgery, including measurement of plasma free $\mathrm{MN}$ and $\mathrm{NM}$ (nmol/L) and/or urinary MN and NM ( $\mathrm{nmol} / 24 \mathrm{~h}$ ) by high-performance liquid chromatography. Chromogranin A (CGA) levels were assessed by radioimmunoassay (CgA-RIA CT; CIS Bio International, Gif-sur-Yvette, France). The upper limits of normal (ULN) of free $\mathrm{MN}$ and NM were 4.05 and $9.8 \mathrm{nmol} / \mathrm{L}$ in plasma and 1,625 and $2,620 \mathrm{nmol} / 24 \mathrm{~h}$ in urine, respectively. The upper reference limit for CGA was $100 \mathrm{mg} / \mathrm{L}$. For the sake of consistency, we present the plasma free $\mathrm{MN}$ and $\mathrm{NM}$ as well as the urinary $\mathrm{MN}$ and NM and the CGA measurements as ratios normalized by the ULN. MN and NM ratios in plasma and urine were used to determine the catecholamine secretion phenotype of the PHEO, as previously described by Eisenhofer et al. [11]: in the adrenergic phenotype, the MN content exceeds $10 \%$ of the combined $\mathrm{MN}$ and NM content, while in the noradrenergic phenotype, the tumors present an increase in $\mathrm{MN}$ content which remains below $10 \%$ of the combined MN and NM content. A subset of the tumors was defined as poorly secreting if the urinary $\mathrm{MN}$ and $\mathrm{NM}$ levels were below 2 ULN.

When available, genetic assessments for germline mutations in $S D H B / D, V H L$, and RET were made. Histopathological evaluation was ultimately considered as the gold standard for the diagnosis of PHEO, and it included the tumor size, the proliferation index assessed by Ki-67 labeling (using the MIB-1 antibody), and the PASS (Pheochromocytoma of the Adrenal Gland Scaled Score) system as previously described by Thompson [12]

\section{${ }^{18}$ F-FDOPA PET/CT Acquisition Protocol}

Images were obtained using a Biograph 6 true point PET/CT scanner (Siemens Medical Solutions, Knoxville, TN, USA). Image acquisition was started $66 \pm 14 \mathrm{~min}$ after the direct intravenous injection of $300 \pm 80 \mathrm{MBq}$ ( $4 \mathrm{MBq} / \mathrm{kg}$ ) of ${ }^{18} \mathrm{~F}$-FDOPA. Neither was carbidopa used for pretreatment nor was fasting required before image acquisition.

The heterogeneity of a lesion was defined during the CT scan procedure by the presence of hemorrhagic and/or necrotic tissue.

Image Analysis and Quantification of ${ }^{18}$ F-FDOPA Uptake

Quantitative parameters of ${ }^{18} \mathrm{~F}$-FDOPA uptake were obtained using IntelliSpace Portal 6.4 ISP (Philipps), and they included the different standardized uptake values (SUV; i.e., $\mathrm{SUV}_{\max }, \mathrm{SUV}_{\text {mean }}$, lesion-to-liver $\mathrm{SUV}_{\max }$, and lesion-to-liver $\left.\mathrm{SUV}_{\text {mean }}\right)$. All ${ }^{18} \mathrm{~F}$ FDOPA PET/CT scans were interpreted by the same physician. All of these values were obtained from the volume of PHEO, which was encompassed by an axial slice-by-slice approach. The SUV is the ratio between the image-derived radioactivity concentration and the whole-body concentration of the injected radioactivity; it was calculated as follows: SUV = radioactivity concentration in a region of interest $(\mathrm{kBq} / \mathrm{mL}) /($ patient weight $[\mathrm{g}] /$ injected dose 
$[\mathrm{kBq}])$. The highest SUV in all the tumor volume was defined as the SUV $V_{\max }$, whereas the average of the SUV was defined as the $\mathrm{SUV}_{\text {mean }}$. A normal liver region was defined by drawing a region of interest to derive tumor-to-background ratios (PHEO-to-liver SUV) in order to facilitate comparisons between patients.

The metabolic burden (MB) was determined to serve as an image-derived index of overall tumor activity per patient, as previously described [13], and was calculated for each adrenal lesion as follows: $\mathrm{MB}=\mathrm{SUV}_{\text {mean }} \times$ tumor volume. If the patient had bilateral PHEO, the whole-body MB was calculated as the sum of the $\mathrm{MB}$ of each lesion.

\section{Primary Culture of Human PHEO}

After resection, the PHEO was cut longitudinally in two parts, and a piece of the tumor zone was dissected and placed in the operating room in CMF HBSS (Hank's Balanced Salt Solution without $\mathrm{Ca}^{2+}$ and $\mathrm{Mg}^{2+}: 0.3 \mathrm{mM} \mathrm{Na} 2 \mathrm{HPO}_{4}, 4.1 \mathrm{mM} \mathrm{NaHCO}, 0.4 \mathrm{mM}$ $\mathrm{KH}_{2} \mathrm{PO}_{4}, 138 \mathrm{mM} \mathrm{NaCl}, 5.3 \mathrm{mM} \mathrm{KCl}, 5.5 \mathrm{mM}$ glucose, $1.2 \mathrm{~mm}$ $\mathrm{CaCl}_{2}, 0.5 \mathrm{mM} \mathrm{MgCl}_{2}$, and $0.4 \mathrm{mM} \mathrm{MgSO}_{4}$ ) supplemented with $0.2 \%$ FBS (fetal bovine serum) and $1 \%$ penicillin/streptomycin. The tumor was cut into small pieces $\left(1 \mathrm{~mm}^{3}\right)$ before centrifugation at $250 \mathrm{~g}$ for $5 \mathrm{~min}$ in complete RPMI (RPMI, 15\% FBS, and 1\% penicillin/streptomycin).

A pellet was resuspended in complete RPMI and settled during 15-30 min at room temperature in order to eliminate blood cells and fat with the supernatant. This step was repeated twice. The tumor pieces were washed in CMF HBSS, centrifugated at $250 \mathrm{~g}$ for $5 \mathrm{~min}$, then dissociated with $1.5 \mathrm{mg} / \mathrm{mL}$ of collagenase $B$ (Roche) with $1 \mathrm{mg} / \mathrm{mL}$ of dispase II (Gibco) in HBSS during 45 min at $37^{\circ} \mathrm{C}$ under moderate agitation. After sedimentation, the supernatant was recovered (fraction 1) and the pellet crushed in CMF HBSS. After renewed sedimentation, the supernatant was recovered again (fraction 2 ). Both fractions were centrifugated for $5 \mathrm{~min}$ at $800 \mathrm{~g}$ at room temperature and resuspended into $3 \mathrm{~mL}$ of complete RPMI. Three hundred microliters of suspended cells were plated on polylysine-coated cover glass (MatTek). The cells were then incubated at $37^{\circ} \mathrm{C}$ in a water-saturated atmosphere with $5 \% \mathrm{CO}_{2}$, and complete RPMI was added the following day.

\section{Carbon Fiber Amperometry}

Only patients with sporadic PHEO and homogeneous lesions on the CT scan were included. Two days after culture, chromaffin cells originating from PHEO were washed with Locke's solution (140 mM NaCl, $4.7 \mathrm{mM} \mathrm{KCl}, 2.5 \mathrm{mM} \mathrm{CaCl}_{2}, 1.2 \mathrm{mM} \mathrm{KH}_{2} \mathrm{PO}_{4}, 1.2$ $\mathrm{mM} \mathrm{MgSO}_{4}, 0.01 \mathrm{mM}$ EDTA, $15 \mathrm{mM}$ HEPES, and $11 \mathrm{~mm}$ glucose; $\mathrm{pH}$ 7.5) and processed for catecholamine release measurements by amperometry as previously described [14].

Briefly, a carbon fiber electrode of $5 \mu \mathrm{m}$ diameter (ALA Scientific Instruments) was held at a potential of $+650 \mathrm{mV}$ compared with the reference electrode $(\mathrm{Ag} / \mathrm{AgCl})$ and approached close to the cells. Secretion of catecholamines was induced by a 10 -s pressure ejection of $100 \mathrm{mM}$ potassium $\left(\mathrm{K}^{+}\right)$solution from a micropipette positioned $10 \mu \mathrm{m}$ from the cell and recorded over $60 \mathrm{~s}$. The amperometric recordings were performed with an AMU130 amplifier (Radiometer Analytical), calibrated at $5 \mathrm{kHz}$, and digitally low-pass filtered at $1 \mathrm{kHz}$.

An analysis of the amperometric recordings was performed as previously described with a macro (laboratory of Dr. R. Borges; http://webpages.ull.es/users/rborges/) written for Igor software (WaveMetrics), allowing automatic spike detection and extraction
Table 1. Clinical, biochemical, and functional characteristics of the 39 patients with $\mathrm{PHEO}$

\begin{tabular}{|c|c|}
\hline \multicolumn{2}{|l|}{ Clinical characteristics $(n=39)$} \\
\hline Age, years & $53 \pm 15$ \\
\hline Female & $22(56 \%)$ \\
\hline \multicolumn{2}{|l|}{ Presentation } \\
\hline Incidentaloma & $13(22 \%)$ \\
\hline Hypertension & $24(60 \%)$ \\
\hline Symptoms related to abdominal mass & $11(27 \%)$ \\
\hline \multicolumn{2}{|l|}{ Paraclinical characteristics $(n=39)$} \\
\hline Germline mutations & $12 / 35$ \\
\hline RET & 3 \\
\hline$V H L$ & 1 \\
\hline NF1 & 3 \\
\hline$S D H B$ & 2 \\
\hline SDHD & 3 \\
\hline \multicolumn{2}{|l|}{ Biochemical analysis } \\
\hline Adrenergic/noradrenergic phenotype & $26 / 13$ \\
\hline Total urinary $\mathrm{MN}$ and NM, ULN ratio $(n=34)$ & $6.3 \pm 6.6$ \\
\hline Urinary $\mathrm{MN}, \mathrm{ULN}$ ratio $(n=37)$ & $7.5 \pm 11.7$ \\
\hline Urinary NM, ULN ratio $(n=37)$ & $6.8 \pm 6.8$ \\
\hline Plasma free $\mathrm{MN}$, ULN ratio $(n=22)$ & $5.5 \pm 8.1$ \\
\hline Plasma free NM, ULN ratio $(n=23)$ & $5.6 \pm 6.1$ \\
\hline $\mathrm{CGA}, \mathrm{mg} / \mathrm{L}(n=30)$ & $345 \pm 443$ \\
\hline \multicolumn{2}{|l|}{${ }^{18} \mathrm{~F}-\mathrm{FDOPA} \mathrm{PET} / \mathrm{CT}$ uptake parameters } \\
\hline $\mathrm{SUV}_{\text {mean }}$ & $8.9 \pm 5.0$ \\
\hline $\mathrm{SUV}_{\max }$ & $10.4 \pm 6.1$ \\
\hline Metabolic burden, $\mathrm{cm}^{3}$ & $260 \pm 375$ \\
\hline \multicolumn{2}{|l|}{ Histology } \\
\hline Size, $\mathrm{cm}$ & $4.5 \pm 2.6$ \\
\hline Bilateral tumor & $2(5 \%)$ \\
\hline Metastatic tumor & $0(0 \%)$ \\
\hline PASS & $1(0-4)$ \\
\hline $\mathrm{Ki}-67$ index & $2(0-6)$ \\
\hline
\end{tabular}

Values are presented as means $\pm \mathrm{SD} /$ (range) or $n(\%)$. PHEO, pheochromocytoma; $V H L$, von Hippel-Lindau tumor suppressor; NF1, neurofibromatosis type 1; SDHx, succinate dehydrogenase; $\mathrm{MN}$, metanephrine; NM, normetanephrine; CGA, chromogranin A; ULN, upper limit of normal; SUV, standardized uptake value; PASS, Pheochromocytoma of the Adrenal Gland Scaled Score.

of spike parameters [15]. The spike parameter analysis was restricted to spikes with amplitudes higher than $5 \mathrm{pA}$. The number of amperometric spikes was counted as the total number of spikes with an amplitude greater than $5 \mathrm{pA}$ within $60 \mathrm{~s}$. We investigated the total number of spikes per cell corresponding to the number of exocytotic events, the quantal size of individual spikes $(\mathrm{Q})$ corresponding to the spike area above the baseline, which is proportional to the amount of amines per granule, and the spike amplitude $\left(I_{\max }\right)$, which corresponds to the maximal flow of catecholamines released per granule.

\section{Statistical Analysis}

For statistical analysis, GraphPad Prism ${ }^{\circledR} 7.0$ (GraphPad Software, San Diego, CA, USA) was used. The data are reported as 
means \pm SD or SEM. Comparative statistical evaluations between groups (biological phenotype clusters or genotype clusters) were accomplished with a Mann-Whitney test followed by Tukey's test for multiple post hoc comparisons. For correlations between parameters of ${ }^{18} \mathrm{~F}$-FDOPA uptake and biological measurements or amperometric experiments, Spearman's rank order was performed. A $p$ value $<0.05$ was considered to be significant for all tests.

\section{Results}

\section{Overall Patient Characteristics}

This study included 39 patients ( 17 males and $22 \mathrm{fe}$ males; mean age $53 \pm 15$ years) who had 41 histologically proven PHEO (2 patients had bilateral tumors). Hypertension was found in 24 patients $(60 \%)$ at the time of diagnosis. Incidentaloma was the mode of presentation in 13 patients (22\%), a proportion higher than the $5 \%$ reported in the literature [16]. Biochemically, an adrenergic secretion phenotype, according to Eisenhofer's criteria, was found in 26 patients (65\%) who presented a mean urinary MN level 11-fold above the ULN. The remaining thirteen patients had a biochemical phenotype in line with an oversecretion of norepinephrine, as their mean level of urinary NM was 6-fold upper the normal limit value (Table 1 ). In total, 6 patients (15\%) were considered as having poorly secreting tumors.

A total of 35 patients were screened for germline mutations, and amongst them, $12(34 \%)$ carried mutations as follows: $\operatorname{SDHD}(n=3), S D H B(n=2), N F 1(n=3), V H L$ $(n=1)$, and RET $(n=3)$. Half of them had already been surgically treated for other contralateral PHEO or parasympathetic paragangliomas.

Finally, the median histopathological PASS was 1 (range $0-4$ ), with a median Ki-67 index of 2 (range 0-6) and a mean tumor size of $4.5 \pm 2.6 \mathrm{~cm}$ (Table 1). While there was no statistically significant difference in tumor size between the adrenergic and noradrenergic phenotypic subgroups, the PHEO were of a significantly smaller size in the 12 patients with germline mutations, including the $5 S D H B / D$ mutations, than in their nonmutated counterparts $(3.1 \pm 2.3$ vs. $6.1 \pm 2.9 \mathrm{~cm}$, respectively; $p=$ $0.005)$.

\section{${ }^{18}$ F-FDOPA PET/CT and Hormonal Secretion Data}

${ }^{18} \mathrm{~F}-\mathrm{FDOPA} \mathrm{PET} / \mathrm{CT}$ data were available for all patients. The mean $S U V_{\text {max }}$ and $S U V_{\text {mean }}$ of the lesions were $10.4 \pm 6.1$ and $5 \pm 3.3$, respectively. The mean tumor volume was $69 \pm 101 \mathrm{~cm}^{3}$ and the mean MB was $260 \pm 375$ $\mathrm{cm}^{3}$. Evaluating the usefulness of ${ }^{18} \mathrm{~F}$-FDOPA PET/CT in the determination of catecholamine secretion, we found a statistically significant positive correlation between the tumor $\mathrm{MB}$ and the corresponding level of 24-h urinary $\mathrm{NM}(r=0.64, p<0.0001, n=36$; Fig. $1 \mathrm{a}), \mathrm{MN}(r=0.49$, $p=0.002, n=35$; Fig. 1b), and combined MN and NM $(r=0.75, p<0,0001, n=33$; Fig. 1c). Similarly, a positive correlation was observed between the tumor $\mathrm{MB}$ and the concentrations of plasma free NM $(r=0.55, p=0.006$, $n=23$; Fig. $1 \mathrm{~d})$ and CGA $(r=0.61, p=0.0005, n=28$; Fig. 1e) but not with plasma $\mathrm{MN}(r=0.11, p=0.6, n=22$; data not shown).

In contrast, there was no correlation between the SUV characteristics of the PHEO ( $\mathrm{SUV}_{\text {mean }}$ or $\mathrm{SUV}_{\max }$ ) and the corresponding concentrations of $\mathrm{MN}$ or $\mathrm{NM}$ either in plasma or in the 24-h urinary sample (data not shown), except for the plasma levels of CGA, for which a positive correlation was observed with both the $\mathrm{SUV}_{\text {mean }}$ and the $\mathrm{SUV}_{\max }$ of the PHEO $(r=0.41, p=0.02$, and $r=0.55, p=$ 0.0019 , respectively; data not shown).

In addition, the 6 poorly secreting PHEO showed a trend for both a lower MB $(p=0.06)$ and a lower size of the tumors $(3.35 \pm 1.2 \mathrm{~cm}$ vs. $5.1 \pm 0.4 \mathrm{~cm} ; p=0.07) \mathrm{com}$ pared to the secreting PHEO. A significantly lower MB was observed in the 12 mutated PHEO as compared to the sporadic PHEO ( $87 \pm 109$ vs. $\left.385 \pm 494 \mathrm{~cm}^{3} ; p=0.008\right)$, mainly due to the fact that the mutated PHEO had a smaller size than the nonmutated tumors (see earlier). Of note, the MB of the mutated PHEO, even when they were smaller, positively correlated with urinary levels of $\mathrm{MN}$ $(r=0.69, p=0.01, n=11$; data not shown), NM ( $r=0.64$, $p=0.03, n=11$; data not shown), and combined $\mathrm{MN}$ and $\mathrm{NM}(r=0.86, p=0.0012, n=10$; Fig. 1f). In the subgroup of PHEO with SDHB and SDHD mutations (MB $24 \pm 23$ $\mathrm{cm}^{3}$ ), we did not find any correlation with urinary levels of catecholamines ( $r=0.4, p=0.75$; data not shown).

At the histopathological level, the PASS and/or the Ki67 proliferation index of the tumor did not correlate one way or another with its corresponding ${ }^{18} \mathrm{~F}-\mathrm{FDOPA} \mathrm{PET} /$ CT uptake parameters (data not shown).

In summary, we found a positive correlation between the MB of the PHEO as calculated by ${ }^{18} \mathrm{~F}$-FDOPA PET/ $\mathrm{CT}$ and their respective circulating (plasma) or excreted (urinary) levels of MN and/or NM. We then wondered if, besides the concentration of MN, the pattern of catecholamine secretion as measured by amperometry could also influence the ${ }^{18} \mathrm{~F}$-FDOPA PET/CT uptake by the tumor.

\section{Amperometry Analysis}

Among our samples, 5 freshly resected PHEO originating from 5 distinct patients ( 2 women and 3 men; all 

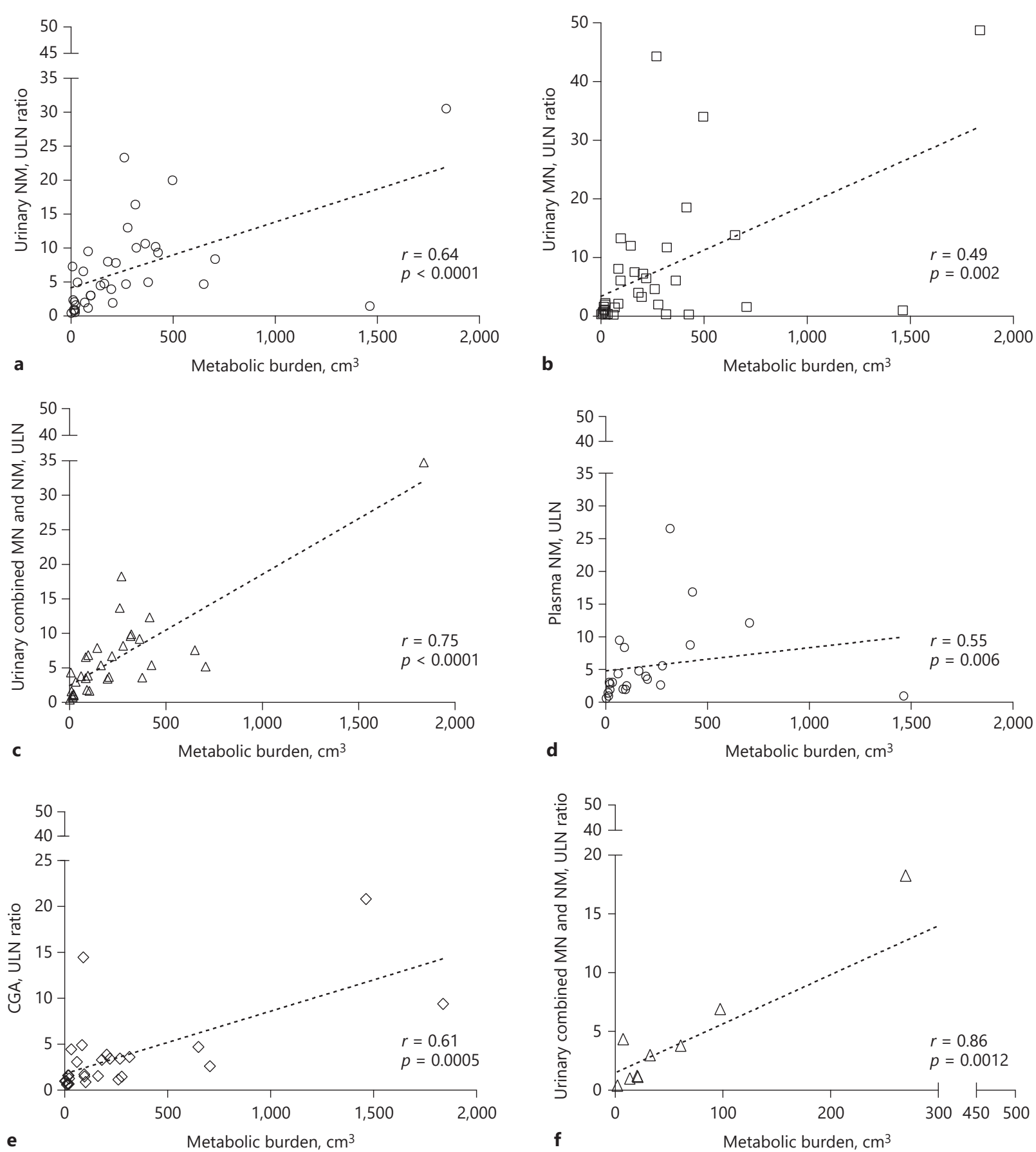

Fig. 1. Correlation between the ${ }^{18} \mathrm{~F}-\mathrm{FDOPA}$ PET/CT metabolic burden of the pheochromocytomas and the respective upper limit of normal (ULN) ratios of 24-h urinary normetanephrine (NM) (a), 24-h urinary metanephrine $(\mathrm{MN})(\mathbf{b}), 24-\mathrm{h}$ urinary combined $\mathrm{MN}$ and $\mathrm{NM}$ (c), plasma free NM (d), plasma chromogranin A (CGA) (e), and 24-h urinary combined MN and NM in the subgroup of mutated pheochromocytomas $(n=11)(\mathbf{f})$. For correlation, Spearman's rank order was performed. 
Fig. 2. a Amperometric recording of catecholamine release after stimulation of one chromaffin cell. b Schematic representation of one amperometric spike. Each spike represents a single granule fusion event, with the surface area or quantal size (Q) being proportional to the amount of catecholamine released per event, and the spike height value $\left(I_{\max }\right)$ displaying the maximal flux of catecholamines. c Correlation between the mean number of spikes recorded by amperometry in primary culture of 5 pheochromocytomas (PHEO) and their corresponding lesion-to-liver maximum standardized uptake value $\left(\mathrm{SUV}_{\max }\right)$ ratio. For correlation, Spearman's rank order was performed.

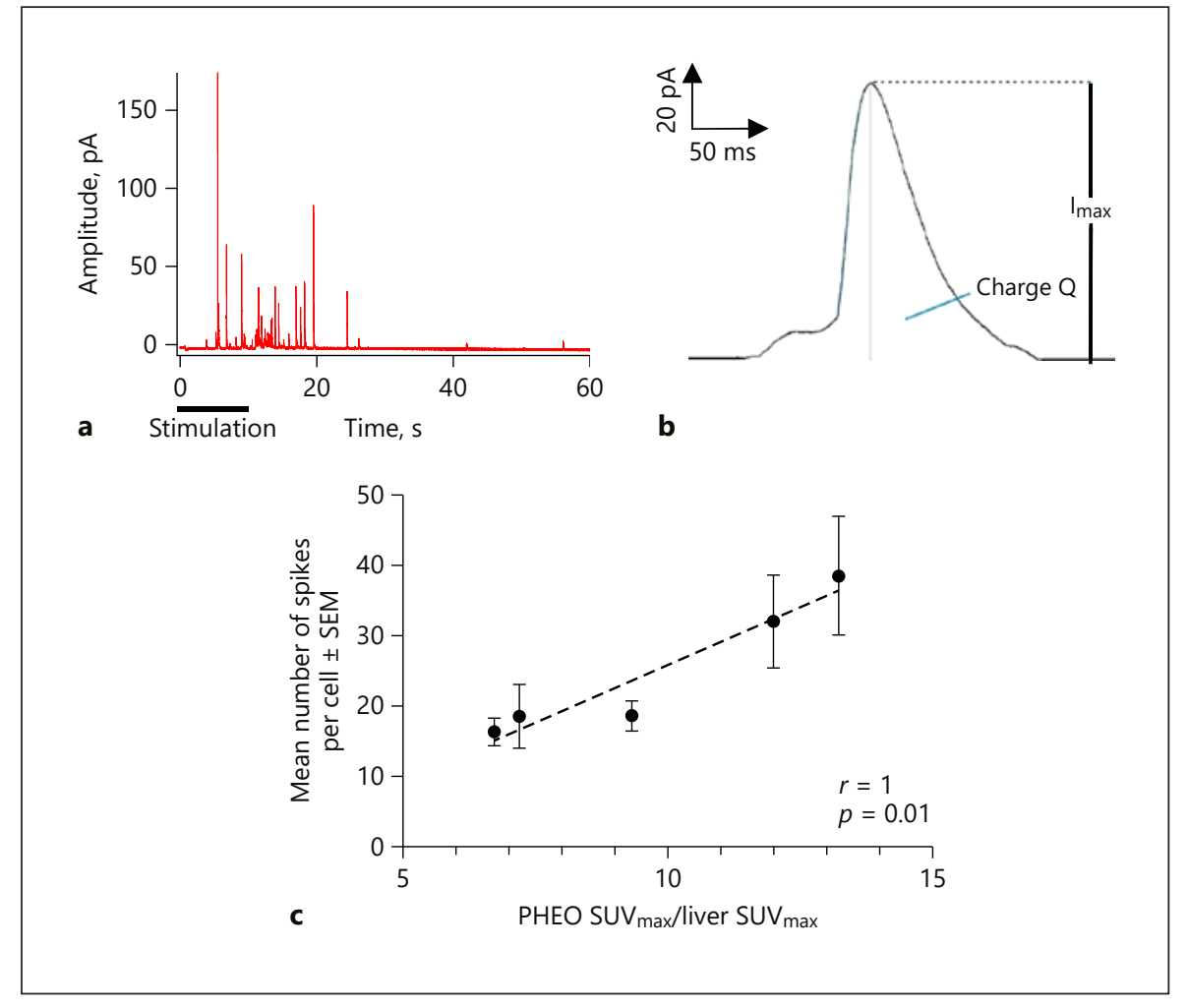

PHEO sporadic, 3 of the adrenergic and 2 of the noradrenergic phenotype) were placed in primary culture in order to perform real-time single-cell catecholamine secretion measurements using carbon fiber amperometry [10]. Tumor chromaffin cells were stimulated with a depolarizing concentration of $\mathrm{K}^{+}$for $10 \mathrm{~s}$ and amperometric spikes were measured over a period of $60 \mathrm{~s}$. A representative amperometric trace recorded from a chromaffin cell cultured from the PHEO of patient 2 is illustrated in Figure 2a. Each spike represents a single granule fusion event, with the surface area or quantal size (Q) being proportional to the amount of catecholamines released per event, and the spike amplitude value $\left(\mathrm{I}_{\max }\right)$ displaying the maximal flux of catecholamines (Fig. 2b). Table 2 summarizes the ${ }^{18} \mathrm{~F}$-FDOPA PET/CT and amperometric parameters for this subgroup of PHEO.

The mean number of spikes detected per cell was $24.7 \pm$ 4.4 , the mean area under the spike trace (Q) was $0.83 \pm 0.12$ $\mathrm{pC}$, and the mean $\mathrm{I}_{\max }$ was $16 \pm 2.0 \mathrm{pA}$. No correlation was found between either the SUV or the MB of the tumor and the corresponding quantal size $\mathrm{Q}$ or the spike height value $I_{\max }$ (data not shown), meaning that the amount of catecholamine stored per secretory granule does not seem to influence the ${ }^{18} \mathrm{~F}$-DOPA uptake of the tumor.
It is noteworthy that we observed for the first time a strictly positive correlation between the lesion $\mathrm{SUV}_{\max } /$ liver $S_{U V} V_{\max }$ ratio and the number of spikes per cell obtained from the corresponding tumor $(r=1, p=0.01$; Fig. 2c), which suggests that the amount of uptake (as reflected in the SUV $V_{\max }$ ) is related to the total number of exocytotic events.

\section{Discussion}

Nuclear medical imaging modalities play a pivotal role in the management of patients with adrenal lesions, especially PHEO [6]. Over the past years, PET/CT examinations have marked a step forward regarding localization, relapse, and assessment of the aggressiveness of the disease. Recent studies also suggest that PET/CT may, in certain circumstances, yield information about the functional status of an adrenal lesion, especially in case of cortisolsecreting lesions [17].

In this study, in a series of 39 operated PHEO we found a positive correlation between ${ }^{18} \mathrm{~F}$-FDOPA MB and the corresponding urinary and/or plasma concentrations of $\mathrm{MN}$ and NM. While only a few studies have been pub- 
Table 2. Clinical, functional, and amperometric characteristics of 5 primary cultures of human pheochromocytomas

\begin{tabular}{|c|c|c|c|c|c|c|c|c|c|}
\hline $\begin{array}{l}\text { Patient } \\
\text { No. }\end{array}$ & Sex & $\begin{array}{l}\text { Tumor size, } \\
\mathrm{mm}\end{array}$ & $\begin{array}{l}\text { Secretion } \\
\text { phenotype }\end{array}$ & $\begin{array}{l}\text { Lesion } \mathrm{SUV}_{\max } / \\
\text { liver } \mathrm{SUV}_{\max }\end{array}$ & $\begin{array}{l}\text { Metabolic } \\
\text { burden, } \mathrm{cm}^{3}\end{array}$ & $\begin{array}{l}\text { Number of cells } \\
\text { analyzed by } \\
\text { amperometry }\end{array}$ & $\begin{array}{l}\text { Mean number } \\
\text { of spikes per } \\
\text { cell } \pm \text { SEM }\end{array}$ & $\begin{array}{l}\text { Mean } \\
\text { charge Q } \pm \\
\text { SEM, pC }\end{array}$ & $\begin{array}{l}\text { Mean amplitude } \\
\mathrm{I}_{\max } \pm \text { SEM, pA }\end{array}$ \\
\hline 2 & M & 37 & $\mathrm{AD}$ & 12 & 84 & 19 & $32 \pm 6.6$ & $0.90 \pm 0.10$ & $21.3 \pm 2.16$ \\
\hline 3 & $\mathrm{~F}$ & 50 & $\mathrm{AD}$ & 9.3 & 220 & 23 & $18.6 \pm 2.2$ & $0.68 \pm 0.05$ & $11.3 \pm 0.81$ \\
\hline 4 & M & 44 & NAD & 6.7 & 378 & 21 & $16.3 \pm 2.0$ & $0.81 \pm 0.10$ & $20.2 \pm 2.71$ \\
\hline
\end{tabular}

SUV, standardized uptake value; $\mathrm{AD}$, adrenergic phenotype; NAD, noradrenergic phenotype.

lished on the topic, some similar observations have been made by others in the past $[9,18,19]$. However, there is still no consensus concerning the best predictive ${ }^{18} \mathrm{~F}$ FDOPA PET/CT uptake parameter to be used in clinical practice. Like ours, the recent study published by Amodru et al. [9] was a retrospective and single-center trial. In their study, 56 patients with a median age of 47.5 years were included. There were fewer patients with a genetic mutational background ( $n=11 ; 19.6 \%)$, including 5 RET, $2 S D H B, 2 S D H D, 1 N F 1$, and 1 VHL mutation. The uptake parameters assessed during the ${ }^{18} \mathrm{~F}$-FDOPA examination included tumor $S \mathrm{SV}_{\text {max }}$, tumor $\mathrm{SUV}_{\text {mean }}$, MTV $42 \%$ (defined by the region enclosed by a $42 \%$ isocontour around the maximal PET voxel), and total lesion uptake, which corresponded to tumor $\mathrm{SUV}_{\text {mean }} \times \mathrm{MTV} 42 \%$. In that study, the tumor $\mathrm{SUV}_{\max }, \mathrm{SUV}_{\text {mean }}$, and tumor $S U V_{\max }$-to-liver $S U_{\text {max }}$ ratio showed a statistically significant correlation with urinary $\mathrm{MN}$ levels. Interestingly, significant positive correlations were observed between the value of urinary MN and MTV $42 \%$ and total lesion uptake, respectively, a result close to the one observed in our study with the MB.

The study by Amodru et al. [9] showed that the $\mathrm{SUV}_{\max }$ of PHEO correlates with the concentration of circulating catecholamines, whereas Imani et al. [19] did not find any statistically significant correlation between the $\mathrm{SUV}_{\max }$ of PHEO and the corresponding biochemical markers. This discrepancy could be due to the $S U V_{\text {max }}$ parameter itself, which is subject to many sources of variability that are not controlled or even taken into account in most reported studies and which reflects a single-pixel value $[20,21]$. The synthesis of catecholamines and their subsequent secretion in PHEO, albeit heterogeneous, are likely to occur in all parts of the tumor, so that whether the $S U_{\text {max }}$ is a reliable tool for predicting the capacity of the tumor to secrete catecholamines is questionable. Un- til now, the $\mathrm{SUV}_{\max }$ has mostly been used to predict the malignancy or proliferative activity $[17,22,23]$ rather than the secretion status of different types of tumors - including adrenal cortical tumors, in which it strongly correlates with the definitive histopathological Weiss score system [24].

Our study shows that the MB of PHEO, which takes into consideration both the mean of the SUV and the volume of the lesion, estimates the concentration of circulating catecholamines, since the "real" measurement of catecholamine secretion by the tumor would require a sophisticated approach including tumor sampling. Two other previous studies also identified a positive correlation between biochemical parameters of medullary thyroid carcinoma and carcinoid tumor and the whole $\mathrm{MB}$ of the tumor as calculated during ${ }^{18} \mathrm{~F}$-FDOPA PET/CT $[25,26]$.

Using the $\mathrm{MB}$ as a predictor of catecholamine concentration is subject to the fact that the size of a PHEO positively correlates with the concentration of $\mathrm{NM}$ and $\mathrm{MN}$, as suggested in a previous study [27]. As such, a trend for a lower MB was observed in our subgroup of poorly secreting PHEO (defined by an intermediate secretion status below 2 ULN) compared to their secreting counterparts. While conducting this study, we wondered if similar concentrations of MN and NM would be observed in a PHEO alternatively secreting high amounts of catecholamines followed by periods of quiescence (i.e., paroxysmal secretion) and in a PHEO which would permanently release moderate levels of catecholamines. While, biochemically, it could lead to similar concentrations, a strong difference remains in terms of the pattern of secretion, and whether the uptake of ${ }^{18} \mathrm{~F}$-FDOPA could be influenced by this pattern of secretion is currently unknown. This hypothesis prompted us to compare, in the second part of this work, the ${ }^{18} \mathrm{~F}$-FDOPA uptake param- 
eters of 5 PHEO with their respective capacity of secretion reflected in the number of exocytotic events obtained after stimulation by amperometric recordings. To the best of our knowledge, we here show for the first time in a translational approach that a positive correlation exists between the PHEO-to-liver SUV max $_{\operatorname{matio}}$ and the mean number of spikes per cell recorded during carbon fiber amperometry. Our results thus suggest that the more important exocytic activity the PHEO has, the more uptake of ${ }^{18} \mathrm{~F}$-FDOPA occurs, leading to high $\mathrm{SUV}_{\max }$ values.

In contrast, no correlation was observed between any of the amperometric parameters of a PHEO and its $\mathrm{MB}$, and several hypotheses may subsequently be discussed. For instance, the MB reflects the metabolic activity of the lesion in its entirety, which means that the result obtained is the synthesis of poorly as well as highly secreting PHEO cells. However, amperometric experiments are conducted on a single cell, being either a poorly, an intermediately, or a highly secreting cell. This could also be the reason why a positive correlation is rather observed with the $\mathrm{SUV}_{\text {max }}$ of a PHEO, since this parameter assesses a highly active zone of the tumor where cells take up considerable amounts of ${ }^{18} \mathrm{~F}$-FDOPA and, therefore, are likely all to be highly secreting. Following this point, it is therefore not surprising to observe that the $\mathrm{MB}$, which represents the whole uptake of a PHEO at the metabolic imaging level, positively correlates with the level of urinary/plasmatic catecholamines, which reflect the secretionary activity of the entire PHEO at the biological level.

An unresolved question that was raised with the amperometric results of our study is the peculiar aspect of head and neck paragangliomas, which are tumors with usually high uptake of ${ }^{18} \mathrm{~F}$-FDOPA but normal concentrations of plasma MN. Most of human paragangliomas, whatever their primary location, express high levels of LAT, the neutral amino acid transporter system $\mathrm{L}$ involved in the uptake of DOPA [28], which may explain their propensity to take up high levels of the radiotracer. However, as compared to PHEO, paragangliomas have a lower expression of the genes involved in catecholamine synthesis (i.e., tyrosine hydroxylase and/or phenylethanolamine $\mathrm{N}$-methyltransferase) $[29,30]$. As such, a hypothesis could be that certain paragangliomas have the molecular equipment required for DOPA uptake, albeit without the capacity to insure catecholamine production and secretion. In order to clarify these questions, amperometric experiments will have to be conducted on paragangliomas.

Finally, our study has obvious inherent limitations due to its retrospective nature. In this respect, we only includ- ed patients with well-characterized biological data and complete ${ }^{18} \mathrm{~F}$-FDOPA PET/CT reports. Because we included surgically treated patients, meaning that a majority of these patients should have been diagnosed with symptoms of catecholamine hypersecretion, correlations might be slightly overestimated. However, an unexpectedly high prevalence of incidental PHEO was noted in our series - at least higher than the one reported in the literature. Also, over the study period, ${ }^{18} \mathrm{~F}-\mathrm{FDOPA}$ PET/CT acquisition has not been performed according to a strict protocol, as is the case in prospective studies, and could therefore be the source of reproducibility bias. To avoid excessive variability between the data, all of our ${ }^{18} \mathrm{~F}$-FDO$\mathrm{PA}$ PET/CT scans were interpreted by the same physician. Finally, there were only a small number of mutated PHEO and a limited representation of specific mutations due to their relative rarity in our series, which also constitutes a limitation of this study. As such, only sporadic PHEO were used in the amperometric analysis, because mutated PHEO do not have the same pattern of ${ }^{18} \mathrm{~F}-\mathrm{FDO}$ PA uptake [7]. Nevertheless, other experiments will have to be performed on this subgroup of patients to confirm or disprove these data.

In conclusion, PHEO are life-threatening tumors which are the source of significant morbidity in clinical practice [31]. Rather than assessing the total amount of catecholamines, it appears critical to improve our understanding of the mechanisms involved in the pattern of secretion displayed by these tumors, as PHEO-induced mortality mainly occurs during an adrenergic storm, when the tumors suddenly release considerable amounts of catecholamines [32]. While the $\mathrm{MB}$ as provided by ${ }^{18} \mathrm{~F}$ FDOPA PET/CT correlates with the concentration of catecholamines, further investigation is needed to specify whether the $S U V_{\max }$ may serve as a reliable tool to predict the secretion pattern of the tumor, as suggested by amperometric experiments.

\section{Statement of Ethics}

The present study was approved by the Ethics Committee of the University Hospital of Nancy (Nancy, France), and informed consent was obtained from each patient.

\section{Disclosure Statement}

The authors have no conflict of interest that could be perceived as prejudicing the impartiality of the research reported. 


\section{Funding Sources}

INSERM provides S.G.'s salary. S.H. benefited from a $\mathrm{PhD}$ fellowship from "Région Alsace" and "Ligue contre le cancer."
Part of this work has been supported by grants from "Ligue contrelecancer" (CCIRGE) and "Fondation ARC"(PJA20141201874) to S.G.

\section{References}

1 Agarwal G, Sadacharan D, Kapoor A, Batra A, Dabadghao P, Chand G, et al: Cardiovascular dysfunction and catecholamine cardiomyopathy in pheochromocytoma patients and their reversal following surgical cure: results of a prospective case-control study. Surgery 2011; 150:1202-1211.

2 Lenders JWM, Duh Q-Y, Eisenhofer G, Gimenez-Roqueplo A-P, Grebe SKG, Murad $\mathrm{MH}$, et al: Pheochromocytoma and paraganglioma: an Endocrine Society Clinical Practice Guideline. J Clin Endocrinol Metab 2014; 99:1915-1942.

3 Favier J, Amar L, Gimenez-Roqueplo A-P: Paraganglioma and phaeochromocytoma: from genetics to personalized medicine. Nat Rev Endocrinol 2015;11:101-111.

4 Fishbein L, Leshchiner I, Walter V, Danilova L, Robertson AG, Johnson AR, et al: Comprehensive molecular characterization of pheochromocytoma and paraganglioma. Cancer Cell 2017;31:181-193.

5 Crona J, Taïeb D, Pacak K: New perspectives on pheochromocytoma and paraganglioma: toward a molecular classification. Endocr Rev 2017;38:489-515.

6 Taïeb D, Timmers HJ, Hindié E, Guillet BA, Neumann HP, Walz MK, et al: EANM 2012 guidelines for radionuclide imaging of phaeochromocytoma and paraganglioma. Eur J Nucl Med Mol Imaging 2012;39:1977-1995.

7 Castinetti F, Kroiss A, Kumar R, Pacak K, Taïeb D: 15 years of paraganglioma: imaging and imaging-based treatment of pheochromocytoma and paraganglioma. Endocr Relat Cancer 2015;22:T135-T145.

8 Jager PL, Chirakal R, Marriott CJ, Brouwers $\mathrm{AH}$, Koopmans KP, Gulenchyn KY: 6-L- ${ }^{18} \mathrm{~F}-$ fluorodihydroxyphenylalanine PET in neuroendocrine tumors: basic aspects and emerging clinical applications. J Nucl Med 2008;49: 573-586.

9 Amodru V, Guerin C, Delcourt S, Romanet P, Loundou A, Viana B, et al: Quantitative ${ }^{18} \mathrm{~F}-$ DOPA PET/CT in pheochromocytoma: the relationship between tumor secretion and its biochemical phenotype. Eur J Nucl Med Mol Imaging 2018;45:278-282.

10 Mosharov EV, Sulzer D: Analysis of exocytotic events recorded by amperometry. Nat Meth 2005;2:651-658.

11 Eisenhofer G, Lenders JWM, Goldstein DS, Mannelli M, Csako G, Walther MM, et al: Pheochromocytoma catecholamine phenotypes and prediction of tumor size and location by use of plasma free metanephrines. Clin Chem 2005;51:735-744.
12 Thompson LDR: Pheochromocytoma of the Adrenal Gland Scaled Score (PASS) to separate benign from malignant neoplasms: a clinicopathologic and immunophenotypic study of 100 cases. Am J Surg Pathol 2002;26:551566.

13 Berkowitz A, Basu S, Srinivas S, Sankaran S, Schuster S, Alavi A: Determination of wholebody metabolic burden as a quantitative measure of disease activity in lymphoma: a novel approach with fluorodeoxyglucose-PET. Nucl Med Commun 2008;29:521-526.

14 Houy S, Estay-Ahumada C, Croisé P, Calco V, Haeberlé A-M, Bailly Y, et al: Oligophrenin-1 connects exocytotic fusion to compensatory endocytosis in neuroendocrine cells. J Neurosci 2015;35:11045-11055.

15 Segura F, Brioso MA, Gómez JF, Machado JD, Borges R: Automatic analysis for amperometrical recordings of exocytosis. J Neurosci Methods 2000;103:151-156.

16 Mansmann G, Lau J, Balk E, Rothberg M, Miyachi $Y$, Bornstein SR: The clinically inapparent adrenal mass: update in diagnosis and management. Endocr Rev 2004;25:309-340.

17 Humbert A-L, Lecoanet G, Moog S, Bouderraoui F, Bresler L, Vignaud J-M, et al: The computed tomography adrenal wash-out analysis properly classifies cortisol secreting adrenocortical adenomas. Endocrine 2018; 59:529-537.

18 Fiebrich H-B, Brouwers AH, Kerstens MN, Pijl MEJ, Kema IP, de Jong JR, et al: 6-[F-18] fluoro-L-dihydroxyphenylalanine positron emission tomography is superior to conventional imaging with ${ }^{123}$ I-metaiodobenzylguanidine scintigraphy, computer tomography, and magnetic resonance imaging in localizing tumors causing catecholamine excess. J Clin Endocrinol Metab 2009;94:3922-3930.

19 Imani F, Agopian VG, Auerbach MS, Walter MA, Imani F, Benz MR, et al: ${ }^{18} \mathrm{~F}$-FDOPA PET and PET/CT accurately localize pheochromocytomas. J Nucl Med 2009;50:513-519.

20 Boellaard R, Krak NC, Hoekstra OS, Lammertsma AA: Effects of noise, image resolution, and ROI definition on the accuracy of standard uptake values: a simulation study. J Nucl Med 2004;45:1519-1527.

21 Keyes JW: SUV: standard uptake or silly useless value? J Nucl Med 1995;36:1836-1839.

22 Guerin C, Pattou F, Brunaud L, Lifante J-C, Mirallié E, Haissaguerre $\mathrm{M}$, et al: Performance of ${ }^{18} \mathrm{~F}$-FDG PET/CT in the characterization of adrenal masses in noncancer patients: a prospective study. J Clin Endocrinol Metab 2017;102:2465-2472.
23 Groussin L, Bonardel G, Silvéra S, Tissier F, Coste J, Abiven G, et al: ${ }^{18} \mathrm{~F}$-fluorodeoxyglucose positron emission tomography for the diagnosis of adrenocortical tumors: a prospective study in 77 operated patients. J Clin Endocrinol Metab 2009;94:1713-1722.

24 Weiss LM: Comparative histologic study of 43 metastasizing and nonmetastasizing adrenocortical tumors. Am J Surg Pathol 1984;8: 163-169.

25 Verbeek HHG, Plukker JTM, Koopmans KP, de Groot JWB, Hofstra RMW, Muller Kobold AC, et al: Clinical relevance of ${ }^{18} \mathrm{~F}$-FDG PET and ${ }^{18} \mathrm{~F}$-DOPA PET in recurrent medullary thyroid carcinoma. J Nucl Med 2012;53: 1863-1871.

26 Fiebrich H-B, de Jong JR, Kema IP, Koopmans KP, Sluiter W, Dierckx RAJO, et al: Total ${ }^{18} \mathrm{~F}$-DOPA PET tumour uptake reflects metabolic endocrine tumour activity in patients with a carcinoid tumour. Eur J Nucl Med Mol Imaging 2011;38:1854-1861.

27 Haissaguerre M, Courel M, Caron P, Denost S, Dubessy C, Gosse P, et al: Normotensive incidentally discovered pheochromocytomas display specific biochemical, cellular, and molecular characteristics. J Clin Endocrinol Metab 2013;98:4346-4354.

28 Feral CC, Tissot FS, Tosello L, Fakhry N, Sebag F, Pacak K, et al: ${ }^{18} \mathrm{~F}$-fluorodihydroxyphenylalanine PET/CT in pheochromocytoma and paraganglioma: relation to genotype and amino acid transport system L. Eur J Nucl Med Mol Imaging 2017;44:812-821.

29 Grouzmann E, Tschopp O, Triponez F, Matter M, Bilz S, Brändle M, et al: Catecholamine metabolism in paraganglioma and pheochromocytoma: similar tumors in different sites? PLoS One 2015; 10:e125426.

30 Isobe K, Tatsuno I, Yashiro T, Nanmoku T, Takekoshi K, Kawakami Y, et al: Expression of mRNA for PACAP and its receptors in intra- and extra-adrenal human pheochromocytomas and their relationship to catecholamine synthesis. Regul Pept 2003;110:213217.

31 Riester A, Weismann D, Quinkler M, Lichtenauer UD, Sommerey S, Halbritter R, et al: Life-threatening events in patients with pheochromocytoma. Eur J Endocrinol 2015;173: 757-764.

32 Reisch N, Peczkowska M, Januszewicz A, Neumann HPH: Pheochromocytoma: presentation, diagnosis and treatment. J Hypertens 2006;24:2331-2339. 